IP Periodica Polytechnica

Transportation Engineering

43(4), pp. 225-231, 2015

DOI: $10.3311 /$ PPtr. 8087

Creative Commons Attribution (i)

RESEARCH ARTICLE

\section{Development of a New Method for Comparing the Cold Start- and the Idling Operation of Internal Combustion Engines}

\author{
István Lakatos ${ }^{1 *}$
}

Received 25 August 2014; accepted after revision 19 March 2015

\begin{abstract}
In case of public transportation, the protection of the environment and the economic operation are highlighted issues. The cold start and the cold operational procedure of buses must be optimal both in the scope of environment protection and economic aspects (fuel consumption, wear and tear). By taking these factors into consideration, we have analysed the relevant influential factors and elaborated such a measuring system with the aid of which the fuel consumption can be measured continuously during the operation. Fuel consumption measurements were accomplished with the aid of a new measuring system during cold operation and running and on the basis of processing and evaluating the findings we have suggested a new operational procedure.
\end{abstract}

\section{Keywords}

environment protection, economic operation, cold start procedure, cold operational procedure, fuel consumption, new measuring system, new operational procedure

\footnotetext{
${ }^{1}$ Department of Road and Railway Vehicle,

1 Relevant factors as regards the cold operation of bus diesel engines

1.1 The comparison of exhaust fume emission and fuel consumption of cold start- and idling operation of diesel engines

In case of applying diesel engines in motor vehicle operation, the dynamic characteristics of the engine are significant. There is a connection between the performance and the economic features, the elements of the system mutually affect one another (Burke, 1993; Al-Hasan, 2007; MacMillan, 2009; Rimkus et al., 2013)

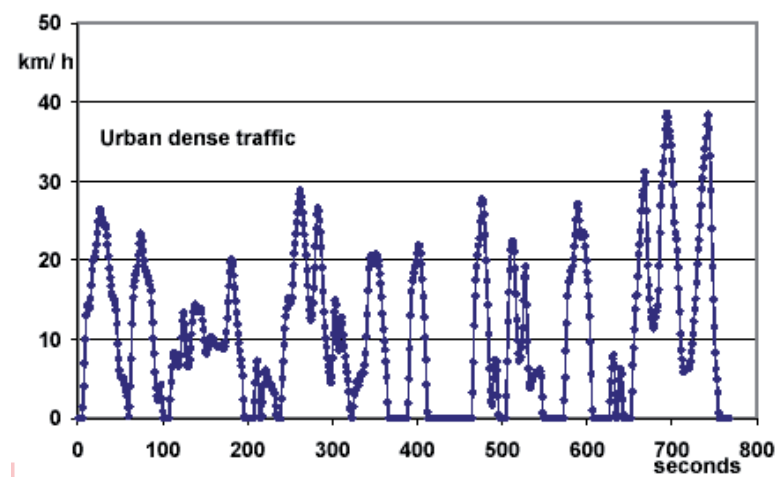

Fig. 1 Frequency of urban dense traffic

The value of fuel consumption projected to $100 \mathrm{~km}$ route significantly increases in case of urban traffic.

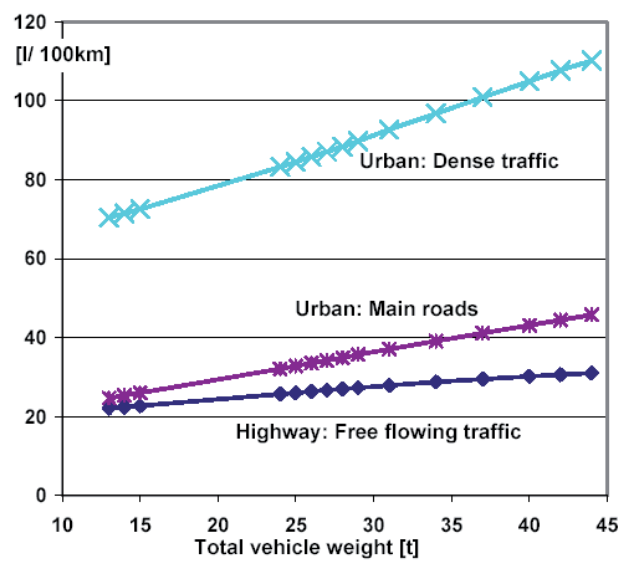

Fig. 2 The relationship between fuel consumption of vehicles and total mass 
As for the emission nearly the two third of such components which burden the environment are generated due to the altering operational conditions, thus the residents' health conditions are at significant risk. This process increases dramatically in case of notable loads and low speed (Helms, 2005; Gaines, 2004; Walsh, 2006; Makareviciene, 2013).

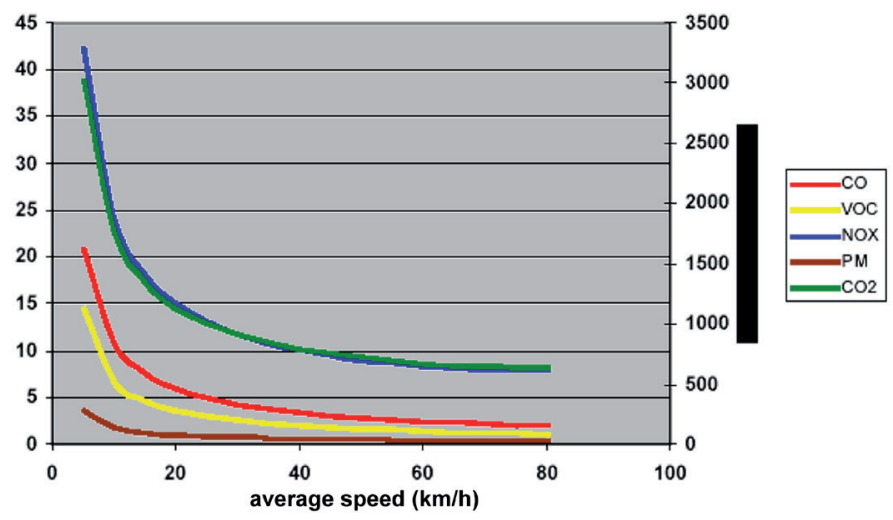

Fig. 3 Vehicle loads and emissions depending on speed

As opposed to the aforementioned ideas the effects emerging during the cold start, the departure and the cold operational procedure in the winter period can mean changeable conditions.

This procedure is characterized by the following factors:

- decreasing performance,

- increasing fuel consumption,

- surplus emission.

Factors which extend the lifetime and diminish the emission can be the following:

- Completing the winter maintenance work and diagnostics in accordance with the regulations.

- Checking the adequate operation of start up charger limiting structure in case of its application.

- After the start-up of the engine the standby state must be ensured, to heat the oil and the components of the engine.

- After the ignition - with suitable driving manner - gradual acceleration and load enhancement must be ensured.

\subsection{The comparison of exhaust fume emission and fuel consumption of cold start- and idling operation of diesel engines}

While the internal combustion engines are in operation the characteristics which are displayed in Fig. 1 influence the tribological processes (Barabas, 2013).

These are the following:

- Normal force (Fn)

- Velocity (v)

- Temperature (T)

- Duration of load (t)

- Friction force (Fr)

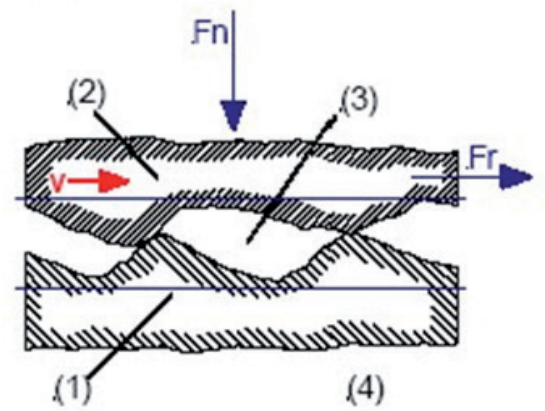

Fig. 4 The basic characteristics of tribological processes

((1) Footling, (2) Anti body, (3) Intermediate material, (4) Environment, Normal force Fn, velocity v,

temperature T, Duration of load t, Friction force Fr, $F_{r}=\mu . F_{n}$ )

In connection with the aforementioned list as regards the cold start of the internal combustion engine and its subsequent running to heat it, as the first process, and as for the running procedure in standby state at operating temperature, as the second process the basic difference is the temperature and the duration of load. Therefore, it is practical to conduct further researches concerning these features. Naturally, besides the primer features enlisted before, the thickness of the lubricating oil film is also significant, however in case of our analysis this is a feature connected to the temperature.

Figure 5 displays the torque of the sliding bearing shaft depending on the thermal condition of the engine (the temperature of the coolant). Along with the drop of the temperature, a nearly linear increase can be detected if we compare it with the 80-85 ${ }^{\circ} \mathrm{C}$ of operating condition.

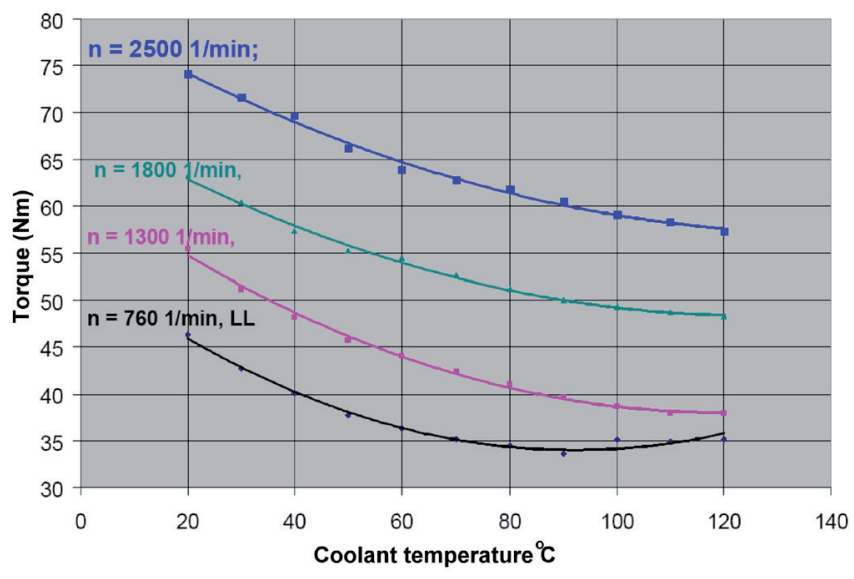

Fig. 5 The torque of the sliding bearing shaft depending on the coolant temperature

Figure 6 shows the change in viscosity of lubricating oil concerning engines in good condition due to repeated cold start (cold start +10 minutes idling). According to the diagram it can be stated that the effect of the change in viscosity is not notable in such a case. 


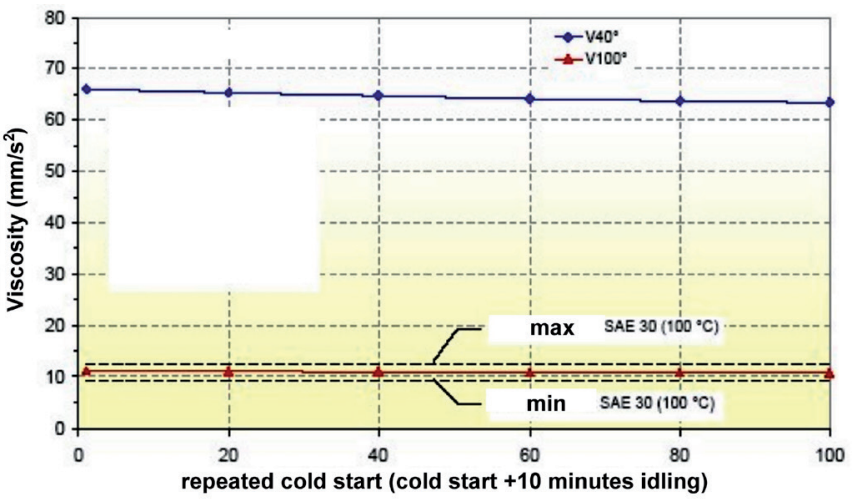

Fig. 6 Change in the viscosity of lubricating oil due to repeated cold start (cold start +10 minutes idling).

According to the analyses the forthcoming can be stated:

As far as wearing is concerned we cannot make a significant difference between the process of the repeated cold start and heating operation, and the process of continuous operation in the standby state. As in one case, the duration of the process, in the other case the operating temperature have more considerable effect on the tribological conditions.

In the forthcoming part, we discuss the effects of the process of cold start and warming up operation on fuel consumption.

\section{Measuring system or measurement method for elaborating a new analyzing method for the evaluation of the cold start- and the average running operation of diesel engines}

\subsection{The elaboration of the measuring system}

The new measuring system was elaborated with the cooperation of ENERGOTEST Kft.

By taking into consideration the preliminary technical consultations and the special requirements of the appointed task we agreed upon measuring the following parameters:

- Measuring fuel consumption in the proceeding and returning section of the engine,

- Measuring fuel consumption in the proceeding and returning section of the pre-heater system,

- Measuring revolution number with optical procedure,

- Measuring the air temperature and humidity of the environment,

- Measuring the air temperature and humidity of intercooler on the side of the engine,

- Measuring the coolant temperature ,

- Measuring the fuel temperature,

- Measuring the oil temperature,

- Measuring the exhaust gas temperature,

- Measuring the turbo pressure,

- Measuring accumulator voltage,

- Measuring the velocity of the vehicle (on the basis of GPS information)
The measurement procedure was to be realized with the sampling frequency per second, the inner memory of the measuring system recorded the measured data.

\section{Elaboration and construction of the new prototype measuring system}

The technical team had already gained adequate experience to accomplish the measuring tasks, however the design of the required complex measuring gauge and recording tool and the construction of the new prototype measuring system meant a challenge.

Consequently a compact gauge adequate for the objectives of the measurement was designed and constructed, which is suitable for receiving the signals of the concerned sensors, for correction and for reliable data storage.

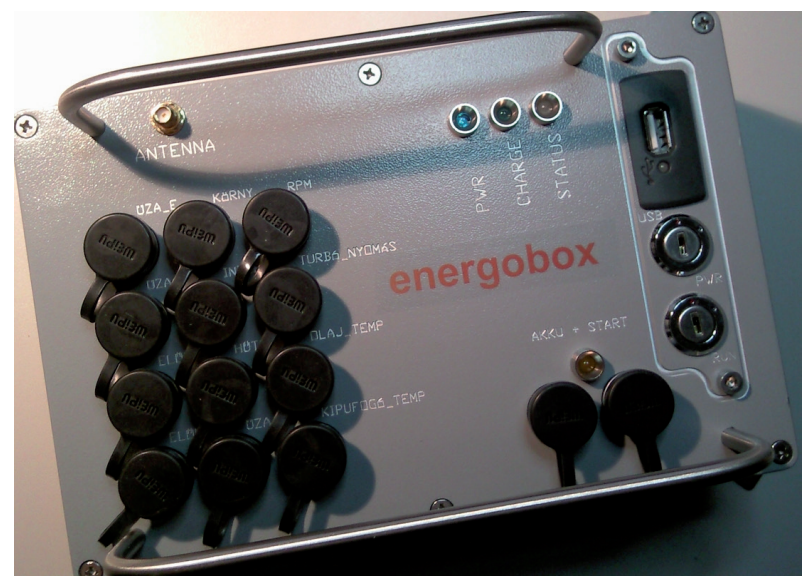

Fig. 7 The designed measuring gauge and data logger

The development work resulted in a small sized gauge that can be easily fixed on a vehicle, without outer intervention. It enables to save the stored data in USB-memory for later process. In its inner memory, it can store nearly one month's measurement results.

The system was directly elaborated to suit to the task specifically defined by the research. We took into consideration the requirements of a later repeated installation and usage, so clear notes and signs were used.

The system is resistant to splashing water and its successful operation is not influenced by extreme weather patterns.

The gadget had been tested before the built-in under such simulated circumstances which could be expected. These sensors are constructed in such a way that it does not cause any difficulty to fix them.

For example, the temperature of the exhaust gas is measured with a platinum sensor that can be fixed on the outlet. It's fixing is easy and does not need the disassembly of the system. Our general viewpoint was - where it was possible - to avoid the disassembly of the systems of the vehicle, rather fix the measuring elements to well-defined points. In case of fuel consumption and the intercooler, the sensors were built-in the system. 


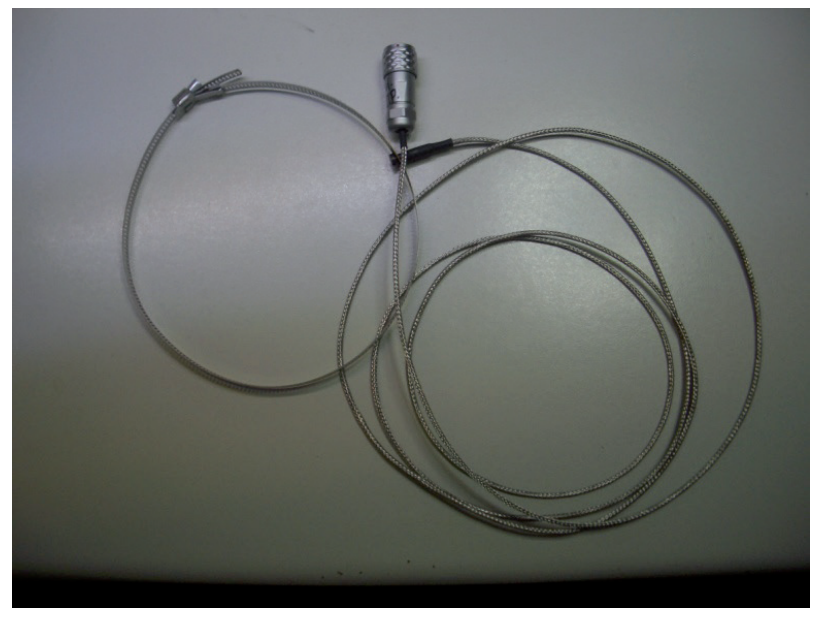

Fig. 8 Sensor for measuring exhaust gas temperature (PT100)

\subsection{The installation of the measuring system}

The system was built in the buses of a public transportation company of a big city. The result of the procedure is verified by the forthcoming figures.
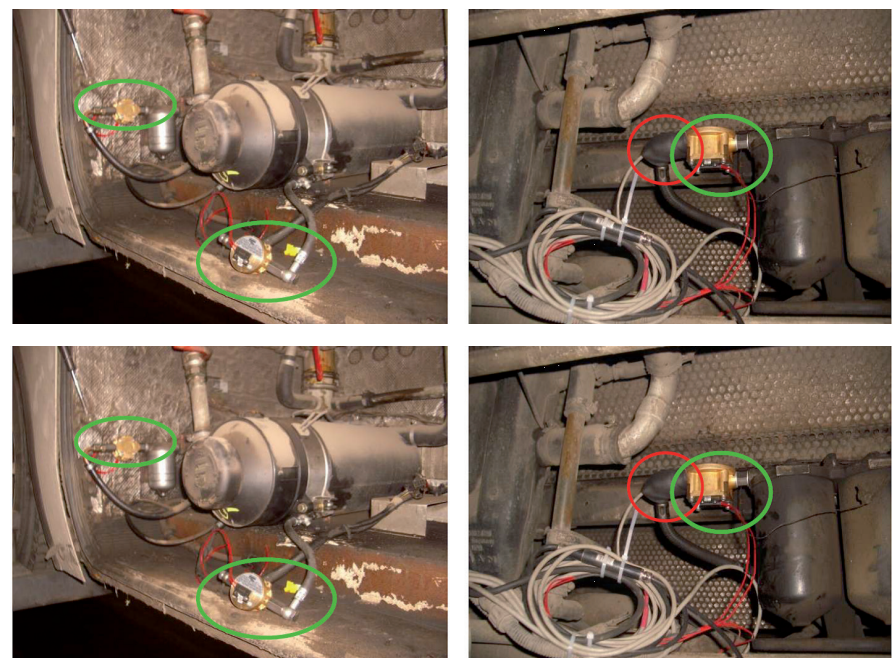

Fig. 9 Measuring means for consumption built in the pipes of the pre-heater and the engine (The heat insulation of the sensor measuring the temperature of the fuel can be clearly seen in the photo on the right- hand side - red circle)

The sensors measuring the output parameters of the air deriving from the intercooler were directly fixed on the engine. The photo indicates that the turbo pressure, the temperature and the humidity sensors were fixed on the lock plate of the chamber.

The temperature of the coolant was also measured without disassembling the system with the help of an insulated sensor possessing heat conducting medium fixed on the piping.

The revolution number was measured with a measuring element operated on optical bases. A structure was constructed for its fixing, which kept the sensor inadequate position. The reflecting area can be seen quite well that reflects the light to the sensor. The diameter of the V-belt pulley of the compressor is the same as the pulley on the main shaft, therefore here the revolution sign is equivalent with the revolution number of the engine.
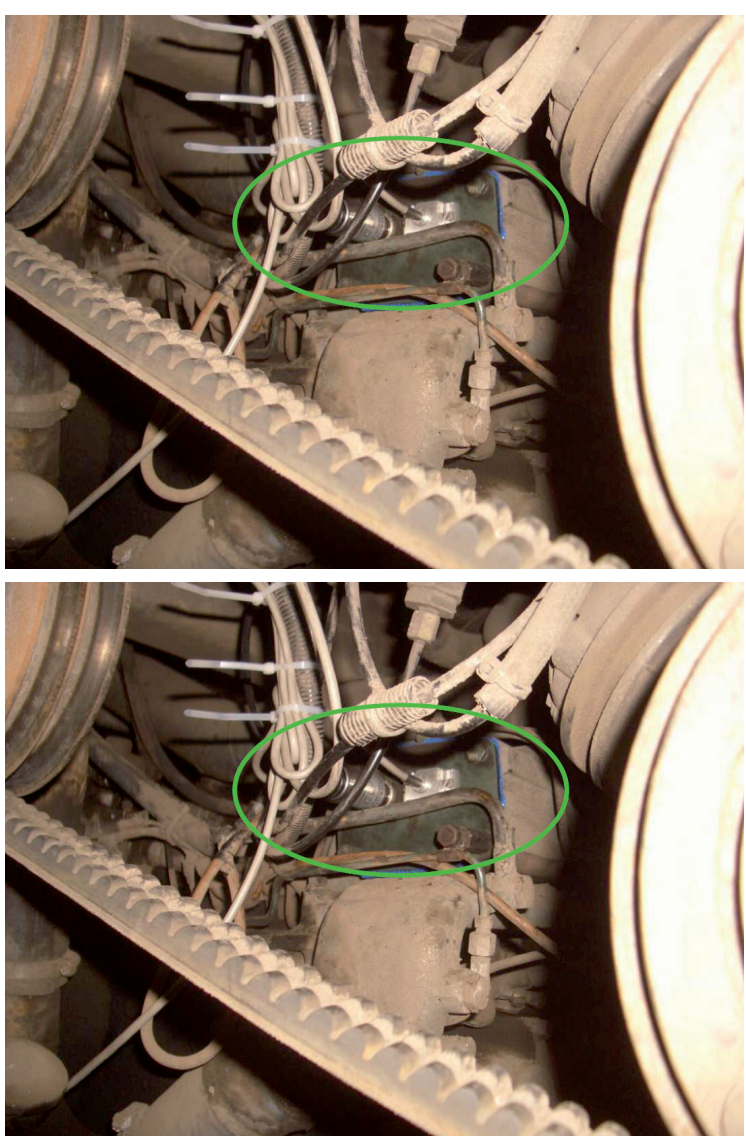

Fig. 10 Measuring the parameters of air intake

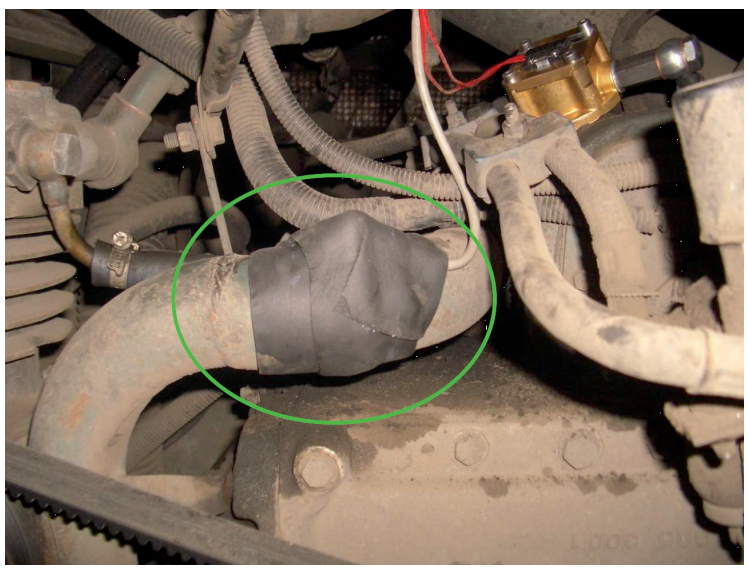

Fig. 11 Measuring the temperature of the coolant with a sensor fixed with insulation

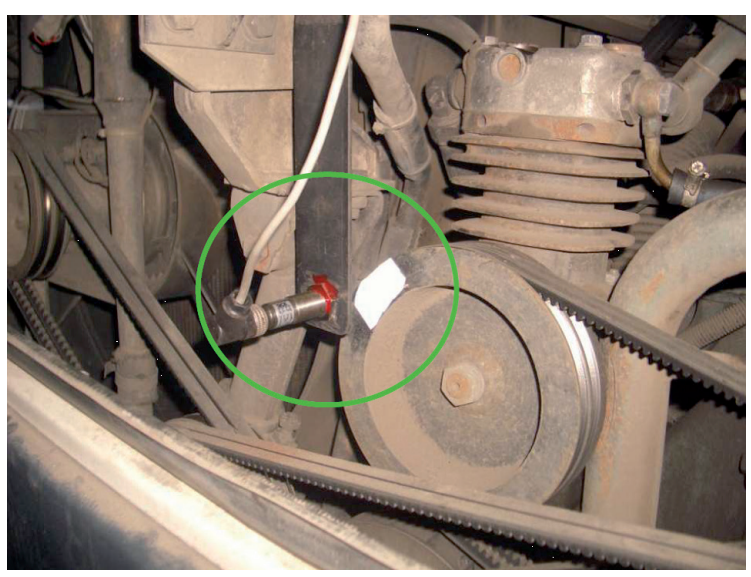

Fig. 12 Optical sensor and measured revolution number by reflecting surface 


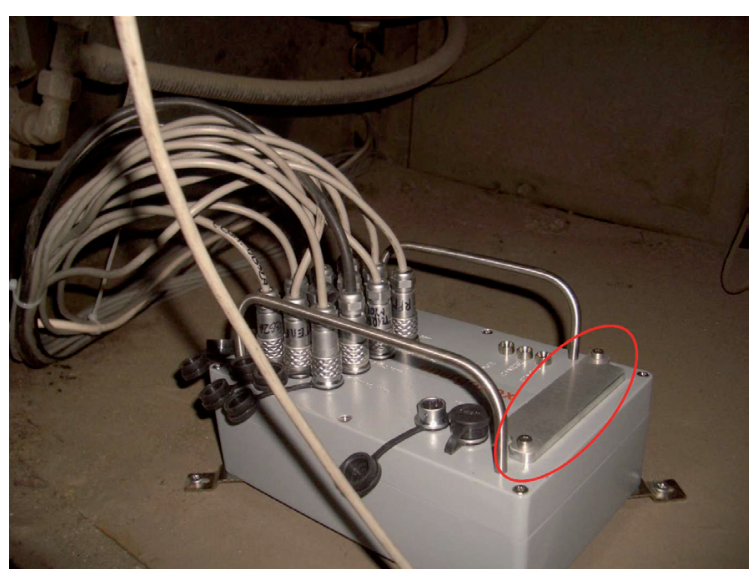

Fig. 13 Installation and location of the data recorder

The data recorder was placed in one of the free cells of the vehicle and the wires of all the sensors were gathered here. The box was fixed to the jacket and water-resistant joints were connected to it. The assembled water confining jacket is clearly visible in the photo, that protects the USB port and the switches.

\subsection{Elaborating the measurement strategy, measuring}

For elaborating the strategy for a new kind of cold operation of the transport company by which it intended to achieve energy savings we planned to accomplish the following measurements:

- Heating the vehicle for operational temperature by using the pre-heater system.

- Heating the vehicle with the aid of pre-heater system to achieve operational temperature $\left(40-50{ }^{\circ} \mathrm{C}\right)$ then

o starting the vehicle, and running for about $10 \mathrm{~km}$ length.

○ with slight load, running for about $10 \mathrm{~km}$ length.

- Starting the engine of the vehicle without heating, then heating the vehicle by the idling operation.

- Starting the engine of the vehicle without heating, then setting off with slight load and running for about $10 \mathrm{~km}$.

\subsection{Data processing, drawing conclusions, elaboration of a new evaluation method}

The evaluation of the data was based on four different methods of starting in case of the chosen buses (measuring of the fuel consumption of $2 \times 10$ days in case of the 3 selected buses per each) thus we created benchmark for defining the optimal starting algorithm:

During the process of the huge quantity of the measured data it was a crucial task to filter and organize the data in such a way to avoid data loss.

This factor was handled with the following method:

1. The hourly data were categorized in eight hours period, so we could state which parts are in connection with starting, or other phenomena affecting fuel consumption.
2. The 'interesting' ranges were also compared with the data about weather conditions.

3. As an end result of this data process, an objective base of comparison was created.

4. These data ranges were brought into a common set of data with mathematical procedures (pattern matching, linear SPLINE-interpolation and recursive error sensing) on the basic points of interpolation.

5. The new set of data is suitable for drawing objective conclusions without data loss or alternation of any valuable data.

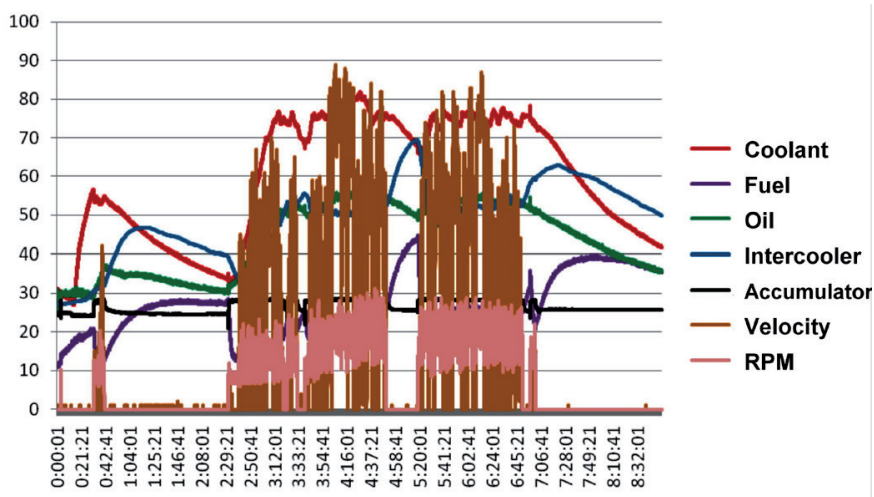

Fig. 14 General ' 8 hours long'diagram from the measuring data of one of the buses (filtered, interpolated)

In the ' 8 hours long' diagram in Fig. 10, the temperature of the coolant was indicated with red colour. It is visible that from the $13^{\text {th }}$ minute the driver of the vehicle used pre-heater system to heat the vehicle until the $30^{\text {th }}$ minute, then ran the vehicle for a short time (no revolution number and no velocity data).

The starting point of the pre-heater is indicated by the slight fall in the voltage of the accumulator, the start of the engine is shown by the significant increase in the accumulator voltage and the appearance of the revolution number. This phase is a highlighted group of data about the fuel consumption of the pre-heater as regards this period.

By using this 'sample', we looked for similar elements in the set of data by taking into consideration the alternation of the temperature related to the unit of time. When we managed to find equal samples in the set of data we regarded them as comparable data and located them in the aggregated database. We examined the measured set of data of all the concerned vehicles with the help of these procedures.

In the final database altogether 140 starting processes of the three vehicles are aggregated.

Considering the circumstances we compiled our aggregated database by paying attention to the alternation of the coolant temperature related to the unit of time as regards different external temperature and we set the corrected steepness of curves on the same temperature basis. Consequently, we made the possibilities for combinability and comparability. 


\section{Evaluation of the measurements and the strategy of a new cold start - heating operation}

In the following part, we analyse the results of the measurements according to the studied (previously defined) starting strategies. (Lakatos, 2011).

\subsection{Heating the vehicle to operational temperature by using pre-heater system}

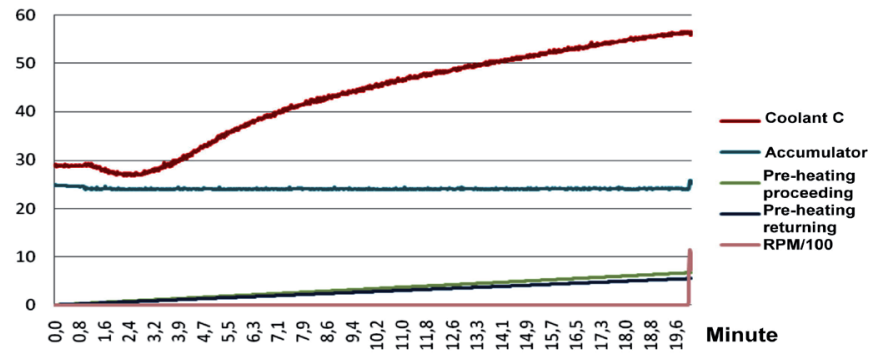

Fig. 15 Heating the vehicle with the pre-heater

It can be visible in the diagram that there is a slight fall of the voltage of the accumulator at the $1^{\text {st }}$ minute, the pre-heater is started then. During the heating time the fuel consumption is linear, the temperature of the coolant shows a slightly shallowing curve.

The duration of pre-heating is 19 minutes, the difference of temperature is $27-28{ }^{\circ} \mathrm{C}$. The driver started the vehicle at the $20^{\text {th }}$ minute, it can be seen on the right-hand side of the diagram that the revolution number appears. The consumed fuel during this period is 1.2 liter.

\subsection{Heating the vehicle with the aid of pre-heater system to achieve operational temperature $\left(40-50^{\circ} \mathrm{C}\right)$ then starting the vehicle, and running for about $10 \mathrm{~km}$ length}

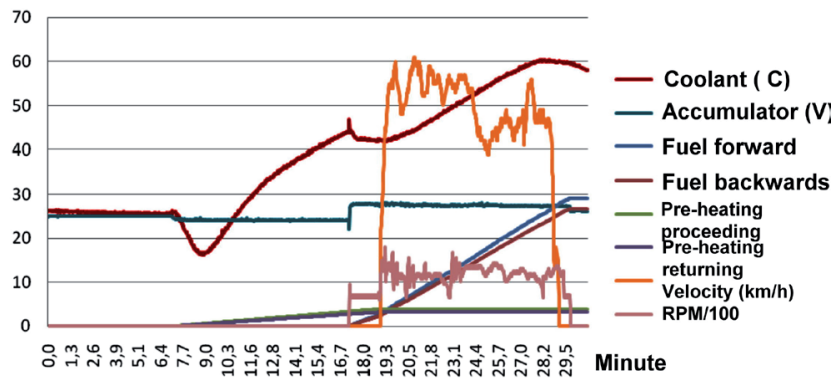

Fig. 16 Pre-heating then starting the vehicle

As it can be seen in the diagram above in this case the vehicle was heated with the help of a pre-heater system up to about $45^{\circ} \mathrm{C}$ and right after the start of the engine we set off. The start of the pre-heater took place at $7,7^{\text {th }}$ minute.

The duration of heating is 11 minutes, the fuel consumption is 0.7 liter, the difference of the temperature is $\sim 30{ }^{\circ} \mathrm{C}$. The operation time of the engine is 13 minutes, the fuel consumption is 2.4 liters, the distance $10 \mathrm{~km}$.
4.3 Heating the vehicle with the aid of pre-heater system to achieve operational temperature $\left(40-50^{\circ} \mathrm{C}\right)$ then starting the vehicle and running for about $10 \mathrm{~km}$ length

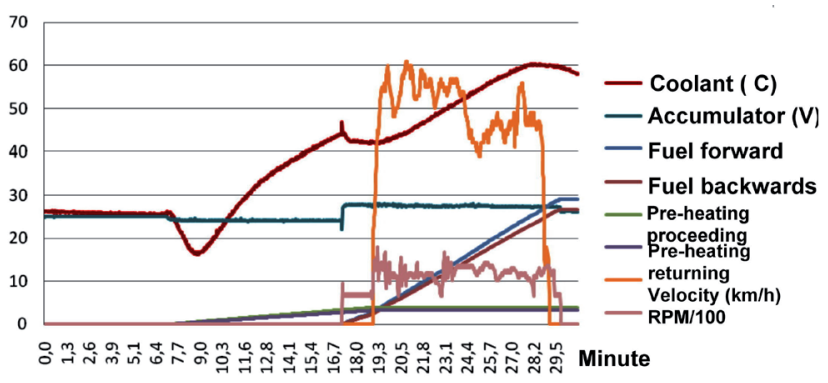

Fig. 17 Heating the vehicle up to $50{ }^{\circ} \mathrm{C}$ at idling operation

In the state summarized in the diagram above the vehicle was heated up to $50{ }^{\circ} \mathrm{C}$ at idling operation after the start of the engine. Taking into consideration the comparability of the diagram we only evaluate the period between $7,5^{\text {th }}-35^{\text {th }}$ minutes as it was the period when the coolant temperature reached the temperature values of the previously aggregated diagrams. After the start of the engine at the $5,6^{\text {th }}$ minute, the engine was running at idling operation. When the coolant temperature reached $50{ }^{\circ} \mathrm{C}$ the vehicle set off and was running until it reached $60-62{ }^{\circ} \mathrm{C}$.

It is clearly visible in the graph that the temperature even reached $65^{\circ} \mathrm{C}$, but it was not recognized by he driver due to the delay of the inner instruments.

The heating period at idling operation is 15 minutes, the heating period with movement is 13 minutes. The difference between the temperature values is $\sim 30{ }^{\circ} \mathrm{C}$. The consumed fuel during the idling operation is 1,80 liter, during movement it is 2,4 liter. The distance is $10 \mathrm{~km}$.

\subsection{Starting the engine of the vehicle without heating then setting off with slight load}

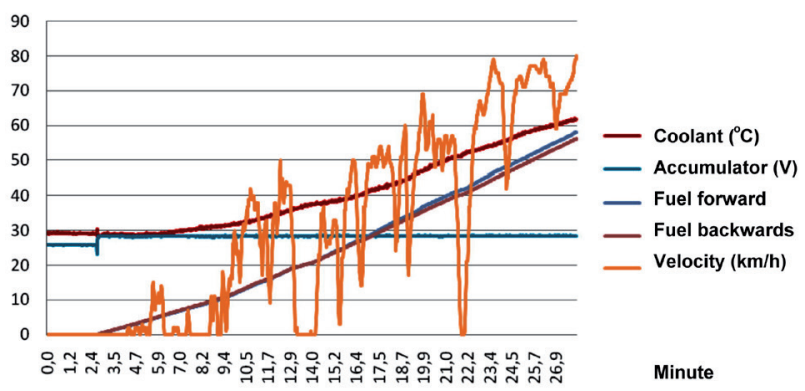

Fig. 18 The vehicle sets off after starting the engine then reaches the operational temperature while it is running

The diagram displays a starting phase. 2minutes after the engine is started - which is indicated by the significant increase of the voltage of the accumulator - the vehicle sets off and 6 minutes after the time of the departure it accelerates and is running 
continuously at considerable speed. It is visible in the diagram that the 6 minutes running of the engine and the slow movement barely increase the coolant temperature. These 6 minutes excluding the nearly 1-minute long 'rolling' can be regarded as idle operation according to the velocity data which caused only a few ${ }^{\circ} \mathrm{C}$ change thus did not affect the results notably.

The duration of heating time during movement is also $\sim 20$ minutes and the difference between the temperature values is $\sim 30{ }^{\circ} \mathrm{C}$. The consumed fuel during the period is 1.9 liter. The distance is $11 \mathrm{~km}$.

\subsection{Elaboration of the strategy of a new cold-start - heating operation}

The four starting methods are described in a summarized matrix similarly to the measurement series.

Table 1 Cumulative evaluation of the measurements

\begin{tabular}{lccccc}
\hline & $\begin{array}{c}\text { Euration } \\
\text { (minute) }\end{array}$ & $\begin{array}{c}\text { Engine } \\
\text { consumption } \\
\text { (l) }\end{array}$ & $\begin{array}{c}\text { Pre-heating } \\
\text { consumption } \\
\text { (l) }\end{array}$ & $\begin{array}{c}\text { Distance } \\
\text { (km) }\end{array}$ & $\begin{array}{c}\text { Total } \\
\text { consumption } \\
\text { (liter) }\end{array}$ \\
\hline 1. & 40 & 2.31 & 1.72 & 10 & 4.03 \\
2. & $\mathbf{2 3}$ & $\mathbf{2 . 4 2}$ & $\mathbf{0 . 6 9}$ & $\mathbf{1 0}$ & 3.11 \\
3. & 32 & 4.7 & - & 10 & 4.7 \\
4. & 17 & 4.7 & - & 10 & 4.7 \\
\hline
\end{tabular}

From the table above it is obvious that the most economic way of cold-start if we consider fuel consumption, is the common use of the pre-heater system and the engine. It is worth to continue heating up to $45-50{ }^{\circ} \mathrm{C}$. After that, the start of the engine and an immediate set off is the optimal solution.

\section{Summary}

After elaborating the measuring system, designing, accomplishing and evaluating the measurements we stated the following procedures about the new cold-start operation as regards the buses of the public transport company:

1. The aforementioned facts verify that the most optimal way of cold-start is to use the pre-heater system for heating the vehicle but maximum up to $50{ }^{\circ} \mathrm{C}$.

2. After that besides slight load of the vehicle the set-off and the running.

3. If the coolant temperature exceeds $40{ }^{\circ} \mathrm{C}$ preheating is not necessary, the vehicle can operate with slight load.

4. Earlier we have mentioned that in case of not too long stops or breaks (if its length does not exceed 1-1.5 hour) the vehicle does not cool at such a rate which suggests the need for a cold-start procedure. Thus, if short breaks can be taken into account during the planning of movement of the vehicle it can mean further savings and more economic operation.
The result of the research work is a newly developed measuring system and measuring procedure with which we constructed a new cold operational procedure.

\section{References}

Al-Hasan, M. (2007) Evaluation of Fuel Consumption and Exhaust Emissions During Engine Warm-up. American Journal of Applied Sciences. 4 (3). pp. 106-111. DOI: 10.3844/ajassp.2007.106.111

Barabás, I. (2013) Predicting the temperature dependent density of biodieseldiesel-bioethanol blends. Fuel. 109. pp. 563-574. DOI: 10.1016/j.fuel.2013.03.001

Burke, J. O. (1993) Electronically Controlled Engine Starting Fluid Injection Systems For Use As Cold Start Assist in Direct Injection (DI) Diesel Engines, Truck Technology International. pp. 1-8. URL: http://www.koldban.com/v/vspfiles/assets/images/documents/ECESF.pdf

Gaines, L. (2004) Truck Idling: Implications and Solutions, Alternatives to Truck Engine Idling Des Moines, Iowa. URL: http://www.ctre.iastate. edu/pubs/truck_idling/gaines.pdf

Helms, H. (2005) Fuel saving by light-weighting for European articulated trucks, Institute for Energy and Environmental Research, Heidelberg. URL: http://www.alcoa.com/global/en/environment/pdf/fuel_saving_by_ lightweighting.pdf

Lakatos, I. (2013) Diagnostic measurement for the effective performance of motor vehicles. Acta Polytechnica Hungarica. 10 (3). pp. 239-249.

Lakatos, I. (2012) Modeling of a Naturally Aspirated Gasoline Engine in the GT-suite Software Environment. In: Fajdiga, M., Klemenc, J. (ed.) IAT 2012 - Innovative Automotive Technology. Dolenjske Toplice, Slovenia, 12-13 April 2012. pp. 77-94.

Lakatos, I. (2010) Instacioner üzemállapotú motorteljesítmény-mérés görgős jármüfékpadon. (Measurement of engine power in instationer operating state on rollbench.) In: Bikfalvi, P. (ed.) microCAD 2010, F Section: XXIV. International Scientific Conference. Miskolc, Hungary, 18-20 March 2010. pp. 33-38. (in Hungarian)

Lakatos, I. (2005) OBD, EOBD (fedélzeti diagnosztika). (OBD, EOBD, onboard diagnostic.) Győr: Minerva-Sop Bt., 2005. (in Hungarian)

Lakatos, I. (2001) Modern emission test of diesel engines in Europe. In: Péter, T. (ed.) Symposium on Euroconform Complex Retraining of Specialists in Road Transport. Budapest, Hungary, 09-15 June 2001. pp. 147-153.

MacMillan, D. J. (2009) Influences on the Cold Start Behaviour of a Diesel Engine at Reduced Compression Ratio, Submitted to the University of Nottingham for the degree of Doctor of Philosophy. URL: http://etheses. nottingham.ac.uk/759/1/MacMillan_thesis.pdf

Makareviciene, V., Sendzikiene, E., Pukalskas, S., Rimkus, A., Vegneris, R. (2013) Performance and emission characteristics of biogas used in diesel engine operation. Energy Conversion and Management. 75. pp. 224-233. DOI: 10.1016/j.enconman.2013.06.012

Rimkus, A., Pukalskas, S., Matijošius, J., Sokolovskij, E. (2013) Betterment of ecological parameters of a diesel engine using Brown's gas. Journal of Environmental Engineering and Landscape Management. 21 (2). pp. 133-140. DOI: 10.3846/16486897.2012.679661

Walsh, M. P. (2006) Global Efforts To Encourage Heavy Duty Vehicle Fuel Economy Improvements, Improving The Fuel Economy of Heavy Duty Fleets. URL: http://www.nescaum.org/documents/improving-the-fueleconomy-of-heavy-duty-fleets/ 